\title{
Nucleotide Excision Repair Lesion-Recognition Protein Rad4 Captures a Pre-Flipped Partner Base in a Benzo[a]pyrene-Derived DNA Lesion: How Structure Impacts the Binding Pathway
}

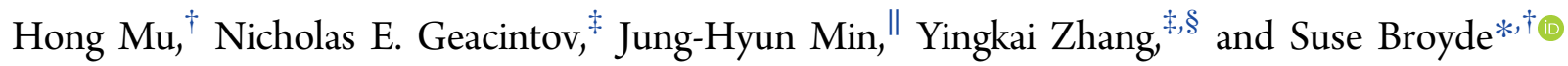 \\ ${ }^{\dagger}$ Department of Biology and ${ }^{\ddagger}$ Department of Chemistry, New York University, New York, New York 10003, United States \\ ${ }^{\S}$ NYU-ECNU Center for Computational Chemistry at NYU Shanghai, Shanghai 200062, China \\ "Department of Chemistry, University of Illinois at Chicago, Chicago, Illinois 60607, United States
}

\section{Supporting Information}

\begin{abstract}
The xeroderma pigmentosum $C$ protein complex (XPC) recognizes a variety of environmentally induced DNA lesions and is the key in initiating their repair by the nucleotide excision repair (NER) pathway. When bound to a lesion, XPC flips two nucleotide pairs that include the lesion out of the DNA duplex, yielding a productively bound complex that can lead to successful lesion excision. Interestingly, the efficiencies of NER vary greatly among different lesions, influencing their toxicity and mutagenicity in cells. Though differences in XPC binding may influence NER efficiency, it is not understood whether XPC utilizes different mechanisms to achieve productive binding with different lesions. Here, we investigated the well-repaired $10 R-(+)$-cis-anti-benzo $[a]$ pyrene- $N^{2}-\mathrm{dG}$ (cis-B $\left.[a] \mathrm{P}-\mathrm{dG}\right)$ DNA adduct in a duplex containing normal partner $\mathrm{C}$ opposite the lesion. This adduct is derived from the environmental pro-carcinogen benzo $[a]$ pyrene and is likely to be encountered by NER in the cell. We have extensively investigated its binding to the yeast XPC orthologue, Rad4, using umbrella sampling with restrained molecular dynamics simulations and free energy calculations. The NMR solution structure of this lesion in duplex DNA has shown that the $\mathrm{dC}$ complementary to the adducted dG is flipped out of the DNA duplex in the absence of XPC. However, it is not known whether the "pre-flipped" base would play a role in its recognition by XPC. Our results show that Rad4 first captures the displaced dC, which is followed by a tightly coupled lesion-extruding pathway for productive binding. This binding path differs significantly from the one deduced for the small cis-syn cyclobutane pyrimidine dimer lesion opposite mismatched thymines [Mu, H., et al. (2015) Biochemistry, 54(34), 5263-7]. The possibility of multiple paths that lead to productive binding to XPC is consistent with the versatile lesion recognition by XPC that is required for successful NER.
\end{abstract}

\section{INTRODUCTION}

Nucleotide excision repair (NER) is a key mammalian defense mechanism against pro-mutagenic DNA lesions that are derived from environmental genotoxins, such as ultraviolet (UV) components of sunlight and polycyclic aromatic chemicals. ${ }^{1,2}$ NER recognizes and repairs a wide range of chemically different DNA lesions; however, their repair efficiencies vary by several orders of magnitude, and some lesions are repaired poorly or not at all. ${ }^{3,4}$ These can escape NER and survive to replication, causing mutations that induce cancer. While the overall stages of NER are known, the reason that chemically different lesions are repaired at very different rates by NER is a topic at the research frontier. The currently accepted hypothesis is that the degree of local thermodynamic destabilization induced by DNA lesions regulates how efficiently the lesion is recognized by the NER system. ${ }^{2,5-11}$

NER repairs lesion-containing DNA through a "cut-andpatch" mechanism: it excises an oligonucleotide of 24-32 residues containing the lesion and restores the DNA sequence through repair synthesis. ${ }^{2}$ The two subpathways of NER, global genomic NER (GG-NER) and transcription-coupled NER (TC-NER), employ a common set of proteins including TFIIH, XPG, XPA, RPA, and ERCC1-XPF, and are essentially the same except for differences in their lesion-recognition mechanisms. ${ }^{2,12-15}$ In TC-NER, the RNA polymerase acts as the lesion sensor; in our current focus of GG-NER, the XPCRAD23B complex detects lesion-containing DNA, aided in cells by centrin 2 and UV-DDB1/2 for cyclobutane pyrimidine dimers (CPDs). ${ }^{16-20}$ UV-DDB1/2 is believed to hand off CPD lesions to $\mathrm{XPC},{ }^{2,21}$ and studies with $\mathrm{CPD}$ lesions in cells suggest that UV-DDB1/2 facilitates NER in chromatin. ${ }^{22}$ The complex of damaged DNA with XPC recruits TFIIH, whose $\mathrm{XPD}$ helicase verifies the lesion enhanced by XPA; ${ }^{2,23-25}$

Received: March 16, 2017

Published: May 1, 2017 
subsequently, other NER factors are recruited to ultimately produce excision of the 24-32-mer damaged oligonucleotide. ${ }^{1}$ Single molecule studies have been employed to study the dynamics of various NER factors including XPC, XPD, and RPA. $^{26-29}$

The key role of XPC in GG-NER lesion recognition has been well established, and NER cannot proceed without this recognition step. ${ }^{7,12,30-37}$ Mutations in XPC cause a xeroderma pigmentosum disease that produces extreme UV sensitivity and skin cancers. ${ }^{38}$ The crystal structure of a Saccharomyces cerevisiae $\operatorname{Rad} 4-\operatorname{Rad} 23$ (herein referred to as $\operatorname{Rad} 4$ ), the yeast orthologue of human XPC-RAD23B, complexed with a DNA duplex containing a CPD lesion shows that the $\beta$-hairpin from BHD3 of Rad4 is inserted into the DNA helix from the major groove, while the $\mathrm{BHD} 2 \beta$-hairpin binds the damaged region from the minor groove side. ${ }^{7}$ Also, it shows that the CPD is extruded from the DNA duplex along with the two mismatched partner bases placed complementary to the CPD. Notably, the $\mathrm{CPD}$ is flipped out away from the protein and disordered, whereas these partner bases are bound to the cleft between BHD2 and BHD3 (Figure S1). This structure, which we call the productive open complex, suggests that BHD3 $\beta$-hairpin insertion and flipping of the two partner bases are crucial elements of lesion recognition in eukaryotic $\mathrm{NER}^{7}$ and are facilitated by lesion-imposed DNA distortions and thermodynamic destabilizations. ${ }^{2,5,6}$

A two-stage binding mechanism for Rad4 has recently been observed through temperature-jump perturbation spectroscopy (T-jump) combined with fluorescence resonance energy transfer (FRET) methods. ${ }^{39}$ These studies revealed a fast nonspecific step $(\sim 100-500 \mu \mathrm{s})$ and a slow specific step $(5-10$ $\mathrm{ms}$ ) when Rad4 binds to a lesion. A "twist-open" mechanism for Rad4 binding was suggested, in which the first step involves fast DNA untwisting, and the second step entails slow, full nucleotide flipping and duplex opening. The rates of these steps are proposed to depend on the nature of the lesion, relating to how much the lesion distorts and destabilizes the DNA. T-jump experiments have also suggested that lesion recognition is under kinetic control via a "kinetic gating" mechanism that would allow efficient recognition of destabilizing lesions. ${ }^{40}$ Single-molecule fluorescence microscopy studies have provided further support for the "twist-open" and the "kinetic gating" lesion recognition mechanisms. ${ }^{29}$

Previously, using molecular dynamics (MD) simulations with umbrella sampling for free energy calculations, we determined the molecular pathway and associated free energy of Rad4 binding to the CPD-containing DNA duplex with mismatched partner $\mathrm{T}$ bases, in the same sequence as in the crystal structure of the productive open complex. ${ }^{41}$ The CPD lesion in the context of mismatches is known to be well-repaired. ${ }^{42,43}$ Along the pathway, we determined the molecular roles of BHD2 and BHD3 in distorting the DNA and opening it for productive binding via a correlated motion mechanism. This study opened the door to investigating the molecular details of Rad4 binding to lesions that are structurally very different, in order to assess how lesion structure impacts the binding pathway. We hypothesize that different lesions, whose impacts on DNA structure and stability vary, may manifest differences in binding pathways and/or energetics. ${ }^{41}$

Accordingly, for the present study we have selected a DNA lesion, 10R-(+)-cis-anti-benzo[a]pyrene- $N^{2}-\mathrm{dG}$ (cis-B $\left.[a] \mathrm{P}-\mathrm{dG}\right)$ (Figure 1A), that is well-repaired by NER in a duplex containing a normal partner C opposite the lesion. ${ }^{8,44,45}$ The
A
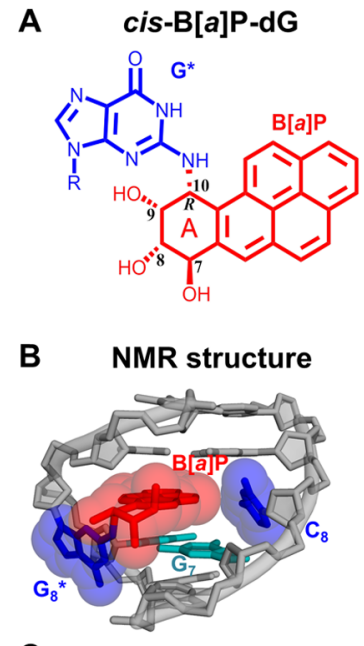

C

DNA sequence

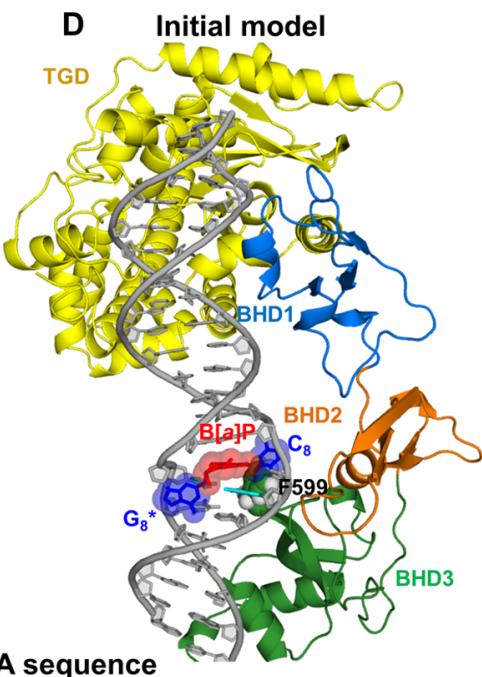

$\begin{array}{llllllllllllllllllllll}1 & 2 & 3 & 4 & 5 & 6 & 7 & 8 & 9 & 10 & 11 & 12 & 13 & 14 & 15 & 16 & 17 & 18 & 19 & 20 & 21 & 22\end{array}$ 5'-T G T A G T C G*C T G A T G T T G A G T C A-3' $3^{\prime}-\mathrm{A} C \mathrm{C}$ A $\mathrm{C}$ A G C G A C T A C A A C T C A G T-5'

Figure 1. (A) Chemical structure of the $10 R-(+)$-cis-anti-benzo[a]pyrene- $N^{2}-\mathrm{dG}$ (cis-B[a]P-dG) lesion. The benzylic ring of $\mathrm{B}[a] \mathrm{P}$ is denoted with an "A". G* denotes the adducted G. (B) The central 5mer of the NMR solution structure for the cis-B $[a] \mathrm{P}$-dG-containing duplex with normal partner $\mathrm{C}^{46}$ The structure of the 5-mer is shown in both cartoon and sticks, with hydrogen atoms and backbone phosphate oxygens hidden. The heavy atoms of the lesion-containing base pair and the $\mathrm{B}[\mathrm{a}] \mathrm{P}$ rings are also shown in transparent spheres. (C) DNA sequence context used for the Rad4-damaged DNA complex. The 5-mer sequence with underlining is the same as the central 5-mer of the NMR solution structure. (D) Initial model of Rad4 and cis-B[a]P-dG-containing DNA (see main text and Supporting Methods). The view is from the minor groove side of the lesion site. The complex is shown in cartoon, the heavy atoms of the cis- $\mathrm{B}[\mathrm{a}] \mathrm{P}-\mathrm{dG}$ lesion are in sticks and transparent spheres, and the side-chain atoms of one key Phe residue (F599) is shown in spheres. The TGD (transglutaminase domain) is yellow, BHD1 (beta-hairpin domain 1) is blue, BHD2 (beta-hairpin domain 2) is orange, BHD3 (beta-hairpin domain 3) is dark green, the DNA is light gray, the $\mathrm{C}_{7}: \mathrm{G}_{7}$ bases are cyan, the $\mathrm{G}_{8}{ }^{*}: \mathrm{C}_{8}$ bases are blue, and the $\mathrm{B}[\mathrm{a}] \mathrm{P}$ rings are red. The side-chain atoms of F599 are color-coded, with carbon in dark green and hydrogen in white.

cis-B $[a] \mathrm{P}-\mathrm{dG}$ in DNA adopts a base-displaced intercalated conformation; in this conformation, the $\mathrm{B}[a] \mathrm{P}$ rings are intercalated from the minor groove into the helix, the adducted $\mathrm{dG}$ is displaced into the minor groove, and its partner base is pre-flipped, extruded into the major groove (Figure 1B). ${ }^{46}$ This structure suggests that its recognition by XPC would be facilitated due to the presence of the flipped-out partner $\mathrm{C}$, as suggested by excision experiments and the Rad4 crystal structure (Figure $\mathrm{S} 1)^{7,47}$ The cis- $\mathrm{B}[a] \mathrm{P}-\mathrm{dG}$ lesion is derived from benzo $[a]$ pyrene $(\mathrm{B}[a] \mathrm{P})$, an important polycyclic aromatic chemical carcinogen that is widespread in the environment, found in vehicle exhaust, tobacco smoke, air, food, and water. ${ }^{4-50}$

In the present study, we have explored many different pathways for the productive binding of the Rad4 to duplex DNA containing the cis-B $[a] \mathrm{P}-\mathrm{dG}$ lesion (Figure $1 \mathrm{C}$ ); this lesion is likely to be encountered by the NER machinery in the cell, given that humans acquire it in their DNA on a regular basis due to both man-made and natural causes. Through this exploration, we have determined how the bulky cis-B $[a] \mathrm{P}-\mathrm{dG}$ supports a binding pathway that differs from that for the smaller 


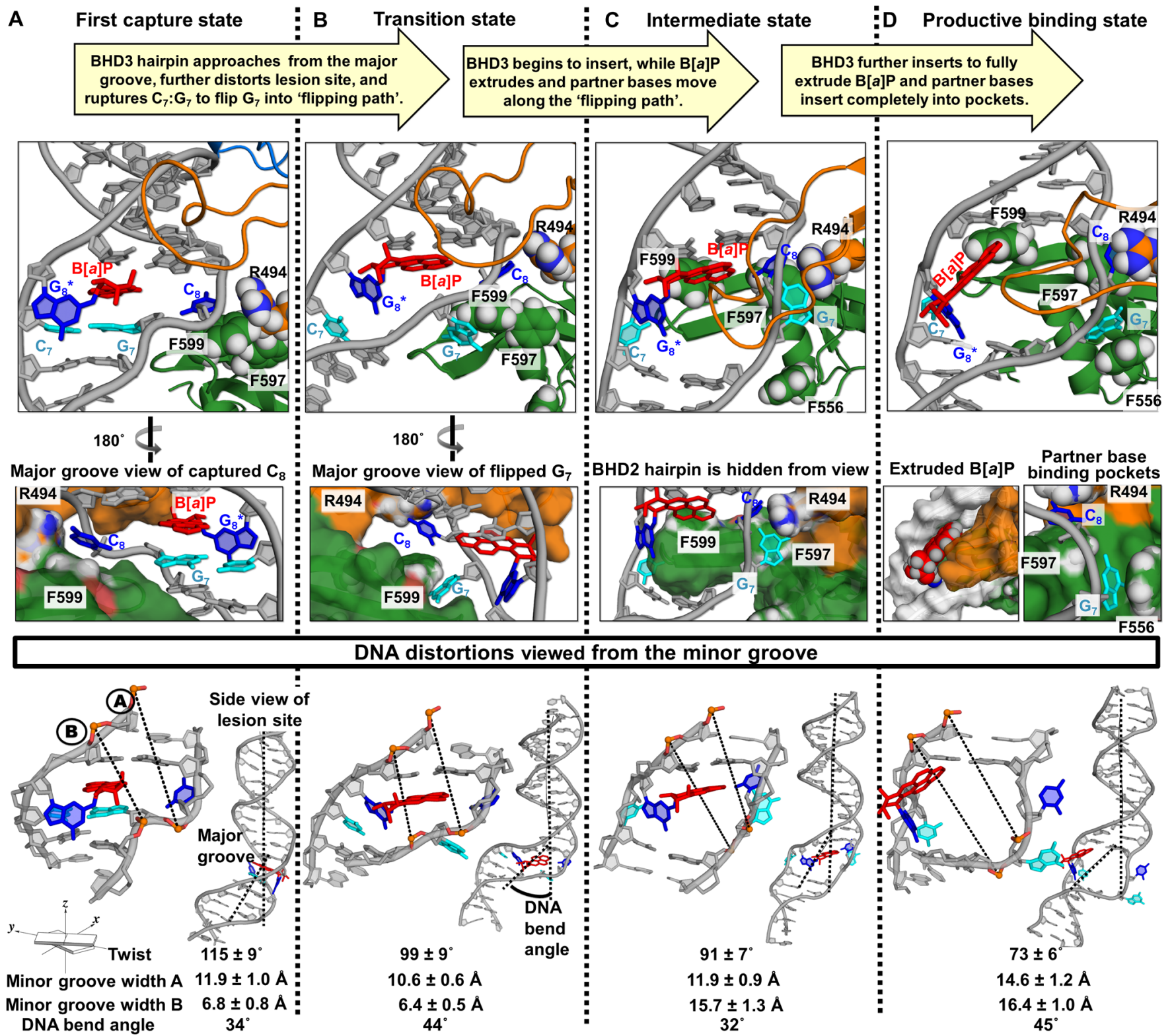

Figure 2. Preferred tightly coupled pathway for productive binding of Rad4 to the cis-B[a]P-dG. (A) First Capture, (B) Transition, (C) Intermediate, and (D) Productive Binding states are shown; see text for further descriptions. The First Capture State structure is the best representative frame of the 300-600 ns ensemble of the unrestrained MD from the initial model (Figure 1 and Figure S5). The Transition, Intermediate, and Productive Binding State structures are the best representative frames from the 30-60 ns ensembles of the umbrella sampling windows for the respective states. The structures are rendered and color-coded as in Figure 1. The side-chains of F556, F597, F599 (the three Phe "flipping path"), and R494 residues are in spheres and are color-coded, with carbon in dark green, nitrogen in blue, and hydrogen in white. Views are into the minor groove of the lesion site, except where indicated. See the Movie S1 for the structures along the dynamic binding pathway. The twist parameter is defined in 3DNA. ${ }^{62}$ The twist angles over five nucleotide steps between $T_{10}: A_{10}$ and $G_{5}: C_{5}$, the top and bottom base pairs of the lesioncontaining 6-mers shown in the figure, are given. Minor groove widths A and B and estimated helix axes to illustrate bend angles are designated by black dashed lines. The pairs of phosphorus atoms for the measurement of minor groove widths are shown as orange balls. The calculations of DNA distortion values are detailed in Supporting Information.

CPD lesion: here, the conformational capture of the pre-flipped partner $\mathrm{C}$ plays an important role in the initial binding to the damaged site; the distinctive process of extruding the bulky intercalated $\mathrm{B}[a] \mathrm{P}$ ring system also highlights how XPC may achieve its versatility in productively recognizing different lesions for NER.

\section{METHODS}

We first created an initial model in order to explore the binding pathway of Rad4 to the cis-B[a]P-dG containing duplex (Figure 1D).
A stable structural ensemble in which the extruded partner $\mathrm{C}_{8}$ (Figure 1C) is first captured by BHD2 and BHD3 of the Rad4, termed the First Capture State, was obtained through unrestrained molecular dynamics $(\mathrm{MD})$ simulation started from the initial model. In order to obtain the molecular pathways toward productive binding and their free energy profiles, we first used umbrella sampling with restrained $\mathrm{MD}$ simulations to generate structural ensembles, starting from the First Capture State toward the productive open complex along selected reaction coordinates (Figures S2 and S3). ${ }^{51}$ We used the AMBER14 package $^{52}$ with the ff14SB force field and a customized force field for the cis- $\mathrm{B}[a] \mathrm{P}-\mathrm{dG}$ lesion, ${ }^{45,53}$ explicit water, and 
counterions. Then, free energy profiles were calculated using the variational Free Energy Profile (vFEP) method for the explored pathways. ${ }^{54}$ The structural properties were calculated using the cpptraj module of AMBER14 and Curves,$+{ }^{52,55}$ and plotted using MATLAB 7.10.0 (The MathWorks, Inc.). All molecular structures were rendered using PyMOL 1.3.x (Schrodinger, LLC.). Full details of force field, molecular modeling, reaction coordinates, and $\mathrm{MD}$ simulations are given in Supporting Methods.

\section{RESULTS}

Pre-Flipped Base $\mathrm{C}$ That Is a Partner to the cis- $\mathrm{B}[\mathrm{a}] \mathrm{P}$ dG Is Captured by BHD2 and BHD3 of Rad4 upon First Encounter. We explored the initial binding of Rad4 to a DNA duplex containing the cis- $\mathrm{B}[a] \mathrm{P}-\mathrm{dG}$ with a normal partner $\mathrm{C}$ (Figure 1C); the initial model (Figure 1D) for this study was based on the NMR solution structure of the damaged duplex (Figure 1B) (see Supporting Methods). ${ }^{46}$ Because of the basedisplaced intercalated conformation of the cis- $\mathrm{B}[\mathrm{a}] \mathrm{P}-\mathrm{dG}$ in the DNA duplex (Figure 1B), the pre-flipped partner $\mathrm{C}_{8}$ (Figure $1 \mathrm{C}$ ) is already positioned toward the surface of $\mathrm{BHD} 3$, where it is ready to be captured by stacking with Phe 599 of the BHD3 $\beta$-hairpin tip; this is the first residue of a three Phe "flipping path" (Phe 599, Phe 597, and Phe 556) identified previously (Figure 1D). ${ }^{41}$ A stable conformation of the complex between Rad4 and lesion-containing DNA, termed the First Capture State, was achieved after $\sim 300$ ns of unrestrained MD simulation starting from the initial model (Figures S4-S6): the pre-flipped partner base $\mathrm{C}_{8}$ is captured in an initial pocket at an interface of $\mathrm{BHD} 2$ and $\mathrm{BHD} 3$; the guanidinium group of Arg 494 in BHD2 hydrogen bonds with a backbone phosphate oxygen of $\mathrm{dC}_{8}$ (Figure $\mathrm{S5B}$ ), and the $\mathrm{C}_{8}$ stacks with the aromatic ring of Phe 599 in BHD3 (Figure 2A). This pocket is created by a set of correlated motions: approach of the positively charged BHD2 residues toward the negatively charged minor groove and DNA backbone; approach of the Phe 599 aromatic ring to the pre-flipped partner base C opposite the lesion; and hinging of $\mathrm{BHD} 3$ toward TGD (transglutaminase domain), which orients the BHD3 $\beta$-hairpin closer to the lesion from the major groove side (Figure S5 and Movie S1).

The approach of BHD2-BHD3 distorts the DNA duplex: $G_{5}: C_{5}$ and $T_{10}: A_{10}$, the end base pairs of the 6-mer sequence around the lesion site, show significant untwisting; the twist angle is $115^{\circ} \pm 9^{\circ}$ for the five base pair steps, compared to the twist angle of the same base pairs in the initial model (based on the NMR solution structure $)^{46}$ which is $142^{\circ}$; the DNA duplex bends toward the major groove around the lesion site with a bend angle of $34^{\circ}$ (Figure 2A). Because of these and other DNA distortions (Table $\mathrm{S} 1$ ), the $\mathrm{B}[a] \mathrm{P}$ rings rotate in plane to slide away from the pre-flipped partner base C (Figure S5). Full details of this First Capture State are shown in Figure 2A and Figure S5.

Preferred Productive Binding Pathway Exhibits Tightly Coupled BHD3 $\beta$-Hairpin Insertion and $\mathrm{B}[\boldsymbol{a}] \mathrm{P}$ Extrusion. We explored many molecular binding pathways of $\mathrm{Rad} 4$ to the cis-B $[a] \mathrm{P}-\mathrm{dG}$ lesion-containing duplex from the First Capture State toward productive binding; in the latter case, the BHD3 $\beta$-hairpin is inserted into the helix at the lesion site, and the partner bases are flipped into the binding pockets at the DNA binding surface of BHD2 and BHD3, as in the crystal structure of the productively bound complex for the CPD-containing duplex. ${ }^{7}$ However, the conformation and location of the cis- $\mathrm{B}[\mathrm{a}] \mathrm{P}-\mathrm{dG}$ lesion is unknown in the productively bound state; the cis- $\mathrm{B}[a] \mathrm{P}-\mathrm{dG}$ is structurally very different from the extruded $C P D$, and it could not be assumed that it was similarly extruded. This presented a challenge to our exploration of binding pathways. In order to achieve productive binding, $G_{7}$ (Figure 1C) must flip into its binding pocket to allow BHD3 hairpin insertion. We found that the free energy barrier for flipping $G_{7}$ along all explored stepwise pathways is always greater than $11.3 \mathrm{kcal} / \mathrm{mol}$, regardless of the order of the steps (Figure S3). Details for an example of energetically disfavored stepwise pathways are given in Figure S3. From these exploratory studies, we learned that the $\mathrm{B}[a] \mathrm{P}$ ring system is extruded into the minor groove to allow stable insertion of the $\mathrm{BHD} 3 \beta$-hairpin for productive binding and that achieving this state requires correlated flipping of $\mathrm{G}_{7}$ into its pocket, BHD3 $\beta$ hairpin insertion, and $\mathrm{B}[a] \mathrm{P}$ extrusion. For our preferred binding process (Figures 2 and S6), we obtained a pathway with tightly coupled structural changes, which produced a Productive Binding State similar to the crystal structure of the Rad4 in complex with a CPD-containing DNA duplex, but the $\mathrm{B}[a] \mathrm{P}$ ring system was extruded to the minor groove (Figures $2 \mathrm{D}$ and S6-S7). The overall free energy profile of the preferred productive binding pathway for $\operatorname{Rad} 4$ to the cis- $\mathrm{B}[a] \mathrm{P}-\mathrm{dG}$ containing duplex is shown in Figure 3.

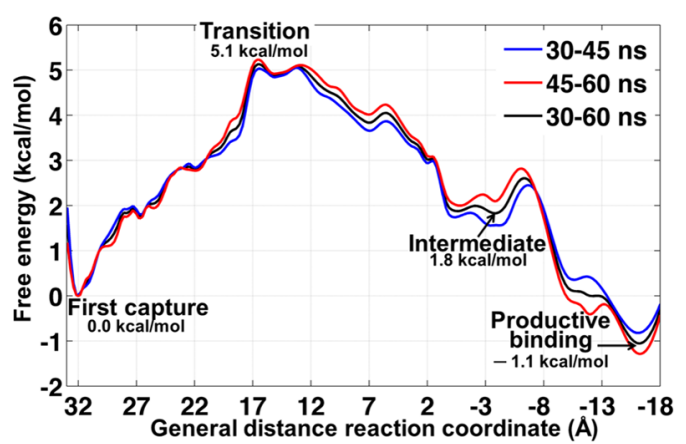

Figure 3. Free energy profile of the preferred pathway for Rad4 productive binding to the cis- $\mathrm{B}[a] \mathrm{P}-\mathrm{dG}$-containing DNA duplex. The indicated states correspond to those in Figure 2. The free energy profiles were calculated for the $30-45 \mathrm{~ns}$ (blue line) and 45-60 ns (red line) time-frames of the umbrella sampling trajectories. The 30$60 \mathrm{~ns}$ free energy profile is shown as a black line, and the values for each state in this profile are given.

From the First Capture to the Transition State: Bending, Untwisting, and Denaturation. Starting from the First Capture State (Figure 2A), both BHD2 and BHD3 $\beta$-hairpins further probe the DNA duplex to distort the lesion site: the DNA duplex bends more toward the damaged strand and untwists around the lesion site; this facilitates rupture of the neighboring $\mathrm{C}_{7}: \mathrm{G}_{7}$ base pair and creates a path for the $\mathrm{B}[\mathrm{a}] \mathrm{P}$ to rotate toward the partner strand and partially extrude toward the minor groove (Figure $2 \mathrm{~B}$ and Movie S1). As the partner base $\mathrm{G}_{7}$ flips into the "flipping path", in which it stacks with the outer edge of Phe 599, the Transition State (Figure 2B), the highest energy point along the pathway, is achieved. Its energy is $5.1 \mathrm{kcal} / \mathrm{mol}$ higher than that of the First Capture State (Figure 3).

In the Transition State structural ensemble, Phe 599 of the $\mathrm{BHD} 3$ hairpin approaches the major groove side of the $\mathrm{B}[\mathrm{a}] \mathrm{P}$ rings, with the $\mathrm{BHD} 3$ hairpin poised for insertion into the duplex to extrude the $\mathrm{B}[\mathrm{a}] \mathrm{P}$ rings (Figures $2 \mathrm{~B}$ and $\mathrm{S} 7$, major groove view). Because of such movements of $\mathrm{BHD} 3$, the 
shallow initial binding pocket for the pre-flipped partner $\mathrm{C}_{8}$ has opened to create a deep binding pocket for productive binding; the pocket is formed by Arg 494 and Phe 597 as the walls, and Met 498 as the floor (Figure 2B). Concomitantly, the preflipped partner $\mathrm{C}_{8}$ has moved across the surface of the Phe 599 phenyl ring, ready to bind into the deep pocket (Figure 2B, major groove view). The flipping partner $\mathrm{G}_{7}$ is stacked with the other side of the Phe 599 phenyl ring, and the N1 and N2 hydrogens of $\mathrm{G}_{7}$ hydrogen bond with the peptide backbone carbonyl oxygens of Glu 600 and Thr 604 in the BHD3 $\beta$ hairpin tip (Figure S7). The lesion site is now denatured since both partner bases are on the "flipping path" (Figure 2B).

Furthermore, the DNA duplex is more bent around the lesion site than that in the First Capture State, with a bend angle of $44^{\circ}$ (Figure 2B). In addition, there is further untwisting compared to the First Capture State: the twist angle is $99 \pm 9^{\circ}$ over the five base pair steps between $G_{5}: C_{5}$ and $\mathrm{T}_{10}: \mathrm{A}_{10}$ (the end base pairs of a 6-mer sequence around the lesion site), $16 \pm 9^{\circ}$ lower than that in the First Capture State (Figure 2B). However, the denaturation does not result in a significant cavity in the duplex because the intercalated multiringed $\mathrm{B}[a] \mathrm{P}$ lesion has turned toward its partner strand to begin extruding toward the minor groove side. Because of the conformational changes of the DNA (bending, untwisting, base flipping, lesion reorientation, and others, Table S1) a wide pocket has formed on the major groove side of the lesion site; this facilitates further association of the BHD3 $\beta$-hairpin and its final insertion for productive binding (Figure S7). Lys 521 at the BHD2 $\beta$-hairpin tip has also stepped down, in the $5^{\prime}$ direction of the damaged strand, toward the $\mathrm{B}[a] \mathrm{P}$ benzylic ring; in this position it establishes hydrogen bonds with the phosphate oxygen of the $\mathrm{dC}_{9}$ nucleotide and electrostatic interactions with the $\mathrm{O} 7$ of the $\mathrm{B}[a] \mathrm{P}$ benzylic ring (Figures $1 \mathrm{~A}$ and S7). Such interactions between the BHD2 $\beta$-hairpin and the lesion site stabilize the $\mathrm{B}[a] \mathrm{P}$ rings for further extrusion into the minor groove toward productive binding.

From Transition to Intermediate State: Initial Insertion of the BHD3 $\beta$-Hairpin with Movement of Flipped Partner Bases along the Flipping Path. Past the Transition State, the complex of Rad4 with the cis-B $[a] \mathrm{P}-\mathrm{dG}$-containing duplex spontaneously converges toward the Productive Binding State as the free energy drops: the BHD3 $\beta$-hairpin gradually inserts, thus fully extruding the $\mathrm{B}[a] \mathrm{P}$ rings into the minor groove, and the flipped out partner bases fully insert into their binding pockets. During this energetically downhill process, the complex transits an Intermediate State where its energy is 3.3 $\mathrm{kcal} / \mathrm{mol}$ lower than that of the Transition State (Figures 2C and 3). At this Intermediate State, BHD3 has hinged away from TGD, toward its conformation in the Productive Binding State, inserting its $\beta$-hairpin tip into the DNA helix at the lesion site. The partner base $\mathrm{C}_{8}$ stacks with the outer edge of Phe 597, and the partner strand $\mathrm{G}_{7}$ rotates its glycosidic bond toward the syn conformation and stacks with the inner edge of Phe 597 (Figure 2C). The twist angle between base pairs $\mathrm{T}_{10}: \mathrm{A}_{10}$ and $\mathrm{G}_{5}: \mathrm{C}_{5}$ has decreased to $91 \pm 7^{\circ}$, and the minor groove has opened greatly, with a width that has increased by $8.9 \AA$ from the First Capture State (Figure 2, minor groove width B). With the insertion of the leading edge of the BHD3 $\beta$-hairpin in the Intermediate State, Phe 599 has begun to approach the flanking base pair $3^{\prime}$ to the lesion and has extruded the already weakly intercalated $\mathrm{B}[a] \mathrm{P}$ rings into the minor groove. The flexible BHD2 $\beta$-hairpin loop has been pushed out to interact with the extruded $\mathrm{B}[a] \mathrm{P}$ moiety and helps shield it from the solvent.
The lesion's conformation in the minor groove is stabilized by electrostatic interactions between the $\mathrm{B}[\mathrm{a}] \mathrm{P}$ benzylic ring and Lys 521, and van der Waals interactions between $\mathrm{Val} 517$ and Thr 516 with the aromatic rings of $\mathrm{B}[a] \mathrm{P}$ (Figure S7).

From the Intermediate to the Productive Binding State: Full Insertion of the BHD3 $\beta$-Hairpin with Extrusion of the $B[a] P$ and Complete Binding of Partner Bases into Their Pockets. From the Intermediate State, the complex converges to the Productive Binding State (Figures 2D and 3), with the energy dropping another $2.9 \mathrm{kcal} / \mathrm{mol}$. The Productive Binding State is $1.1 \mathrm{kcal} / \mathrm{mol}$ lower in energy than the First Capture State (Figure 3). At the Productive Binding State, the BHD3 $\beta$ hairpin is inserted in a manner similar to that in the crystal structure of the productively bound complex of Rad4 with the CPD-containing duplex: the side-chain of Arg 601 stacks with $\mathrm{T}_{6}$ and Phe 599 stacks with the base pair $\mathrm{C}_{8}: \mathrm{G}_{8}$ (Figures $2 \mathrm{D}$ and S7). Moreover, the overall conformation of Rad4 converges to that of the crystal structure of the productively bound complex (RMSD of the resolved peptide backbone heavy atoms is $1.6 \AA$ ) (Figure S7). The partner base $\mathrm{C}_{8}$ is fully inserted into its binding pocket, formed by Arg 494, Phe 597, and Met 498 (Figures $2 \mathrm{D}$ and $\mathrm{S} 7$ ). The flipped-out partner nucleotide $\mathrm{dG}_{7}$ is in the syn conformation, captured by its binding pocket in BHD3: specifically, the six atom ring of $\mathrm{G}_{7}$ stacks with Phe 556 on one side, and $\mathrm{G}_{7}$ is also stabilized by van der Waals interactions with Val 594, Phe 597, and Pro 607 on the other side; in addition, there are hydrogen bonds between the $\mathrm{O} 6$ of $\mathrm{G}_{7}$ and the side chain amino groups of Asn 554 and Asn 558 (Figures $2 \mathrm{D}$ and $\mathrm{S} 7$ ). The fully extruded cis-B $[a] \mathrm{P}-\mathrm{dG}$ lesion is in the minor groove and is stabilized in a $3^{\prime}$ oriented direction along the damaged strand, sandwiched between the DNA backbone and the flexible BHD2 $\beta$-hairpin loop (Figure 2D), where the aliphatic portion of Lys 521 provides van der Waals interactions with the $\mathrm{B}[a] \mathrm{P}$ rings (Figure $\mathrm{S} 7$ ). The bend angle of the DNA is $45^{\circ}$ around the lesion site, the twist angle between base pairs $T_{10}: A_{10}$ and $G_{5}: C_{5}$ is $73 \pm 6^{\circ}$, reflecting severe unwinding over the five base pair steps, and the minor groove width at the lesion site (minor groove width B in Figure 2D) is $16.4 \pm 1.0 \AA$. These molecular depictions of the local distortions upon productive binding are in consonance with experimental permanganate footprinting studies that revealed distortions in a local 6-mer sequence containing this lesion bound to human XPC. ${ }^{45}$

Details concerning the interactions observed at the various stages of the binding pathway are given in Figures S5 and S7, and Table S2 provides hydrogen bond occupancies, distances, and angles as well as their selection criteria. Movie S1 shows the structures along the dynamic binding pathway.

\section{DISCUSSION}

Delineated Pathways Provide Molecular Portrayals of Rad4 Binding Stages to Lesion-Containing DNAs. Experimental studies of Rad4 binding kinetics using T-jump and FRET methods reflect distortions of the DNA duplexes during the binding process. ${ }^{39}$ These experiments have revealed a two-stage binding mechanism: a fast initial binding phase resulting in DNA distortion, proposed to be untwisting, followed by a second slow binding stage which leads to the productive open complex. Our studies of Rad4 binding to two different damaged DNA duplexes, the present cis-B $[a] \mathrm{P}-\mathrm{dG}$ and the CPD-containing duplexes, ${ }^{41}$ have revealed molecular details of the initial binding states and of the binding pathways that lead to the productive open complex that complement 
A Rad4 binding path to cis-B[a]P-dG-containing DNA duplex

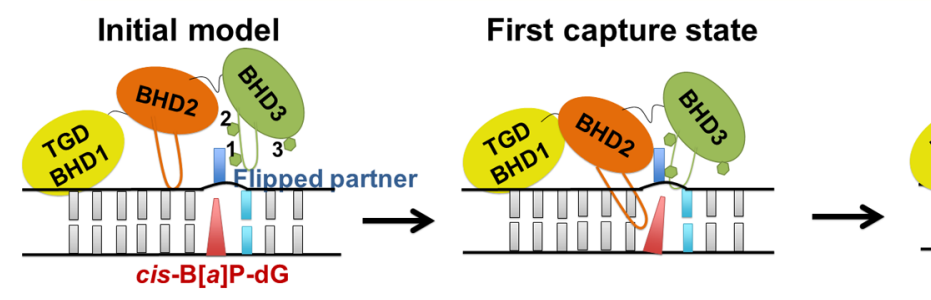

\section{Transition state}

\section{Productive binding state}
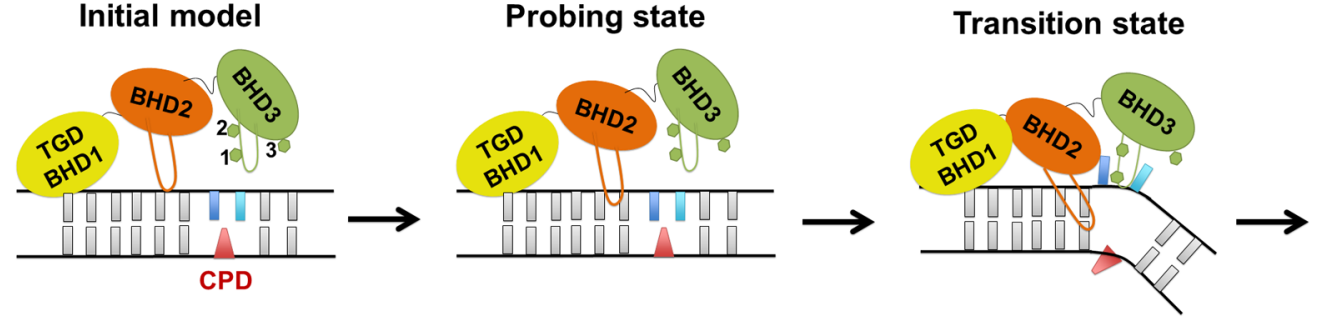

Productive binding state

Figure 4. Preferred binding pathways of Rad4 to cis-B $[a] \mathrm{P}-\mathrm{dG}$ and $\mathrm{CPD}$-containing DNA duplexes differ due to their distinct lesion site conformations. Initial model: for cis-B[a]P-dG, pre-flipped partner C is near the edge of F599 (green hexagon, 1) due to its enlarged minor groove; for $\mathrm{CPD}$, the mismatched partner T bases are not flipped and are distant from BHD3 (Figure 5). First Capture State for cis-B[a]P-dG: the flipped partner C has been captured by BHD2 and BHD3, stacking with F599, and the BHD2 $\beta$-hairpin has bound extensively in the minor groove. For $\mathrm{CPD}$, by contrast, the initial model leads to a Probing State, in which only the BHD2 hairpin tip contacts the minor groove and BHD3 does not associate. Transition State: for cis-B $[a] \mathrm{P}-\mathrm{dG}$, a second partner strand base has flipped out to stack on the opposite face of F599, and the B[a]P rings have begun to extrude toward the minor groove; for $\mathrm{CPD}$, two mismatched partner $\mathrm{T}$ bases have flipped out in concert upon binding of BHD2 and $\mathrm{BHD} 3$, and the CPD has extruded into the major groove, leaving an open site. Productive Binding State: for cis-B $[a] \mathrm{P}-\mathrm{dG}$, this state is achieved by tightly coupled BHD3 hairpin insertion and full lesion extrusion; for CPD, it is achieved just by BHD3 hairpin insertion. In the productive binding state, for both cases, the BHD3 hairpin is similarly inserted: F599 stacks with a neighboring base pair flanking the opened lesion site, and F597 and F556 (green hexagons, 2 and 3, respectively) stack with the flipped out partner bases; however, the $\mathrm{B}[\mathrm{a}] \mathrm{P}$ rings are extruded to the minor groove, while the CPD is extruded to the major groove.

experimental studies. However, the Rad4 binding process to cis$\mathrm{B}[\mathrm{a}] \mathrm{P}-\mathrm{dG}$ or $\mathrm{CPD}$-containing DNA duplexes has shown significant differences in the details of both initial binding states and productive binding pathways. Nonetheless, both binding processes share two important commonalities: (1) sensing of the damaged DNA by the BHD2 $\beta$-hairpin from the minor groove is essential to achieving the initial binding states, and (2) lesion site denaturation is the rate-determining process that leads to the productive open complex; denaturation occurs by association of the $\mathrm{BHD} 3 \beta$-hairpin from the major groove side, together with capture of the flipped partner bases via the three Phe "flipping path" (Phe 599, Phe 597, and Phe 556, Figure 2).

BHD2 $\beta$-Hairpin Is the Initial Sensor of the Damaged DNA That Probes the Duplex from the Minor Groove Side. For both cis-B $[a] \mathrm{P}-\mathrm{dG}$ and $\mathrm{CPD}$-containing DNA duplexes, the BHD2 $\beta$-hairpin approaches the minor groove side of the local region around the lesion upon initial binding. Although the extents and details of the interactions between the BHD2 $\beta$ hairpin and the minor groove are different for the two structurally very different lesions, association of the BHD2 $\beta$ hairpin with the minor groove of the lesion site in both cases leads to DNA distortions (e.g., untwisting and bending) in the initial binding states (Figure 2 and Figure S5 in ref 41). These results are in accord with experimental studies. The T-jump study of Rad4 binding kinetics using mutant XPC, with BHD3 deleted, revealed that $\mathrm{BHD} 3$ is not required for the initial binding stage. ${ }^{39}$ In addition, in a recent single molecule study of Rad4 diffusion along lesion-containing DNA duplexes, atomic force microscopy of mutant Rad4 revealed that deletion of BHD3 does not significantly impact damage-specific binding and DNA bending. ${ }^{29}$ With human XPC and UV lesions in human cells, it has been shown that BHD3 deletion diminishes binding only modestly; however, binding is greatly reduced when a $\beta$-turn of $\mathrm{BHD} 2,19$ amino acids at the interface between $\mathrm{BHD} 2$ and $\mathrm{BHD} 3$, together with $\mathrm{BHD} 3$ is deleted. ${ }^{56}$ These findings point to an important role for BHD2 in lesion binding. Hence, the characteristics of our initial binding states are in consonance with the experimentally identified fast initial binding stage that does not require BHD3. ${ }^{39}$ In our work, we have pinpointed $\mathrm{BHD} 2$ as the main domain that senses the damaged DNA for initial binding, and we have observed unwinding and bending at the initial binding state. This sensing of the damaged DNA by the BHD2 $\beta$-hairpin on the minor groove side implies that lesions with different impacts on the minor groove structure would affect this initial binding stage differently.

DNA Denaturation to Open the Duplex Governs the Free Energy Barrier for Productive Binding. The crystal structure of Rad4 with a CPD-containing duplex and our binding pathways for the CPD and for the cis-B[a]P-dG have shown that BHD3 $\beta$-hairpin insertion from the major groove is essential for stabilizing the productively bound complex of Rad4 with damaged DNA. ${ }^{7,41}$ Our productive binding pathways show that denaturation of the lesion site, the flipping of the partner base/ bases to open the lesion site for the subsequent BHD3 $\beta$ hairpin insertion, is required to achieve productive binding. Experimental measurements of lesion-opening kinetics using Tjump methods reflect the opening, which was shown to be a slow phase following the fast initial Rad4 binding. ${ }^{39}$ Although our productive binding pathways have revealed different molecular details of this process for the different damaged 
A

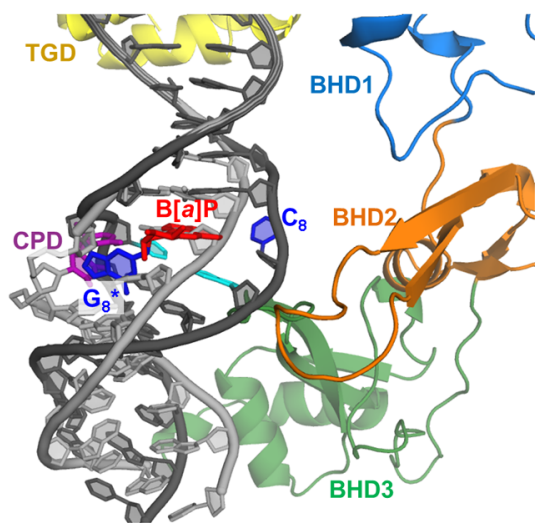

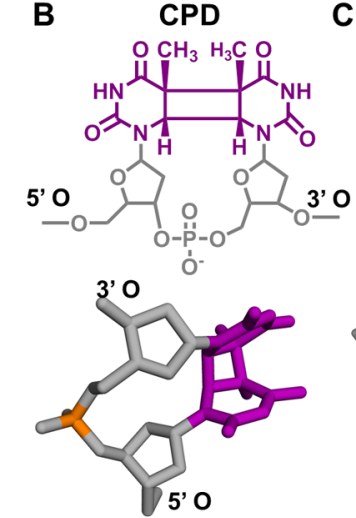

C Comparison of minor groove dimensions

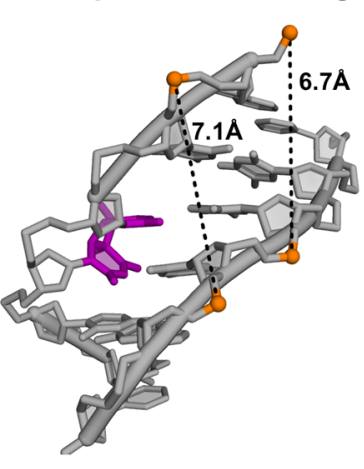

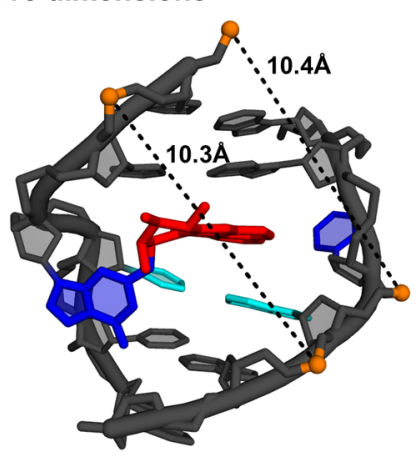

Figure 5. (A) Comparison of initial models for the cis-B $[a] \mathrm{P}-\mathrm{dG}$ (this work) and CPD complexes with Rad4 ${ }^{41}{ }^{\text {The }}$ cis-B $[a] \mathrm{P}-\mathrm{dG}$-containing duplex is dark gray with the $\mathrm{C}_{7}: \mathrm{G}_{7}$ bases in cyan, the $\mathrm{G}_{8}{ }^{*}: \mathrm{C}_{8}$ bases in blue, and the $\mathrm{B}[\mathrm{a}] \mathrm{P}$ in red. The CPD-containing duplex is light gray, wtih the thymine dimer of CPD in purple. On the left, the CPD overlaps with the G8* of the cis-B $[a] \mathrm{P}-\mathrm{dG}$ in this view. (B) Chemical and 3D structures of the CPD lesion. In the 3D structure, the heavy atoms are shown in sticks with the thymine dimer in purple and the phosphorus atom in orange. (C) Comparison of minor groove dimensions of the initial models. Minor groove widths are designated by black dashed lines between pairs of DNA backbone phosphorus atoms and correspond to minor groove widths $\mathrm{A}$ and $\mathrm{B}$ in Figure 2 from top right to lower left. Lesion-containing 6-mer sequence, $G_{5}: C_{5}$ to $T_{10}: A_{10}$, of each initial model is shown in cartoon and sticks. Hydrogen atoms and DNA backbone phosphate oxygen atoms are hidden. The structures are color-coded as described in A. The pairs of phosphorus atoms for the measurement of minor groove widths are shown as orange balls.

duplexes (detailed below), these pathways suggest an essential role for the $\mathrm{BHD} 3 \beta$-hairpin in distorting the DNA around the lesion site, to produce the denaturation/opening needed for productive binding.

For both cis-B $[a] \mathrm{P}-\mathrm{dG}$ and $\mathrm{CPD}$-containing DNA duplexes, the damaged DNAs in the initial binding complexes are further distorted (bent and untwisted) by approach of the BHD3 $\beta$ hairpin from the major groove toward the transition states (Figures 2 and 3 in ref 41), where the denaturation is accomplished. Thus, denaturation is the most energetically demanding process, involving the flipping of the partner base/ bases to open the lesion site for the following BHD3 $\beta$-hairpin insertion. Although the detailed steps of denaturation are different for these two damaged duplexes, there are common structural features, as the transition state is achieved: DNA distortions induced by BHD3 weaken the base pairing at or around the lesion site, and a three Phe "flipping path" in BHD3 facilitates flipping and capture of the partner base/bases. Neither the mutant with deleted BHD3 or deleted BHD3 $\beta$ hairpin was able to "fully" flip out the nucleotides at the lesion site. $^{39,40}$ With the BHD3 $\beta$-hairpin deleted, Phe 597 and Phe 599 are missing; these residues play key roles in providing the path for the flipping partner bases to be properly routed into their binding pockets.

We hypothesize that lesions which structurally hinder the approach of the BHD3 $\beta$-hairpin from the major groove side and/or prevent denaturation around the lesion site may greatly increase the free energy barrier at the transition state and prevent productive binding. An example of a lesion that may block BHD3 $\beta$-hairpin insertion from the major groove side is the NER resistant thermally stabilizing $\left(\Delta T_{m}=T_{m \text {-modified }}-\right.$ $T_{m \text {-unmodified }}=+10{ }^{\circ} \mathrm{C} ; T_{m}$ is the melting temperature of the DNA duplex) $14 R-\mathrm{DB}[a, l] \mathrm{P}-\mathrm{dA}$-containing duplex, in which the five ring $\mathrm{DB}[a, l] \mathrm{P}$ (dibenzo[a,l]pyrene) is intercalated into the helix from the major groove side and well-stacked with adjacent base pairs, and the adducted $\mathrm{dA}$ retains base pairing with its partner dT. ${ }^{9}$

Specific Mechanisms of Rad4 Binding Are Determined by the Distinct Structural Properties of the
Damaged DNA Duplexes. Key differences between the Rad4 binding pathways to the cis- $\mathrm{B}[a] \mathrm{P}-\mathrm{dG}$ and $\mathrm{CPD}$-containing duplexes are summarized in Figure 4. Our preferred Rad4 binding pathway for the cis-B $[a] \mathrm{P}-\mathrm{dG}$-containing duplex exhibits significant differences in detail to the preferred binding pathway for the CPD-containing duplex that was previously investigated, $^{41}$ although their free energy barriers are close. These differences stem from the very different structural properties of these two lesions: the cis- $\mathrm{B}[\mathrm{a}] \mathrm{P}-\mathrm{dG}$ has its large aromatic ring system intercalated into the DNA duplex from the minor groove side, with the adducted $G$ in the minor groove and the pre-flipped partner base $\mathrm{C}$ extruded into the major groove (Figure 1). However, the small CPD lesion has the linked thymines stacked into the helix (Figure 5A), ${ }^{41,57,58}$ and mismatched partner $\mathrm{T}$ bases are also stacked-in. ${ }^{41}$

These structural differences are clearly demonstrated in the initial models for these two lesions (Figure 5A,B). For the CPD case, the lesion partner strand is not in close contact with $\mathrm{BHD} 2$ or $\mathrm{BHD} 3$. However, for the cis- $\mathrm{B}[\mathrm{a}] \mathrm{P}-\mathrm{dG}$ case, the partner strand is closer to the BHD2 and BHD3 hairpin tips due to its enlarged minor groove (Figure $5 \mathrm{~A}, \mathrm{C}$ ); this proximity places the flipped partner $\mathrm{C}_{8}$ in contact with Phe 599 at the BHD3 hairpin tip, ready for capture by BHD2 and BHD3.

Differences revealed in the initial models that incorporate MD-equilibrated experimental lesion-DNA structures (see Supporting Methods) determine differences in the subsequent Rad4 initial binding for the two lesions (Figures 4 and 5). For the cis-B $[a] \mathrm{P}-\mathrm{dG}$ case, when the extruded partner base $\mathrm{C}_{8}$ is first captured (Figure 2A), both BHD2 and BHD3 are closer to the DNA duplex than in the initial model (Figure S5); the BHD2 hairpin now binds extensively in the minor groove $3^{\prime}$ to the lesion, and the BHD3 hairpin is oriented for insertion into the helix. However, for the CPD case, starting from the initial model (Figure 5A), the binding of $\operatorname{Rad} 4$ is first achieved by the BHD2 hairpin tip contacting the minor groove side at the lesion site, while BHD3 does not associate with the DNA duplex (the Probing Model in ref 41) (Figure 4).

The intercalated $\mathrm{B}[a] \mathrm{P}$ rings provide a unique structural impediment to the opening of the damaged DNA duplex for 
BHD3 insertion: the aromatic ring system stacks with the $G_{7}$ partner strand base that must flip and thereby obstructs its flipping. In order to achieve energetically feasible $G_{7}$ flipping, our results showed that this flipping has to be coupled with $\mathrm{B}[\mathrm{a}] \mathrm{P}$ extrusion. In our preferred pathway, tightly coupled $\mathrm{B}[a] \mathrm{P}$ extrusion into the minor groove, $\mathrm{G}_{7}$ flipping along the "flipping path" to the binding pocket, and BHD3 $\beta$-hairpin insertion from the major groove side provide a free energy barrier of $5.1 \mathrm{kcal} / \mathrm{mol}$ to denature the lesion site (Transition State, Figures $2 \mathrm{~B}$ and 3); subsequently, in an energetically downhill process the $\mathrm{B}[a] \mathrm{P}$ rings become fully extruded into the minor groove, and the BHD3 $\beta$-hairpin is fully inserted. It is interesting that the NMR solution structure of this adduct reveals a minor conformational component that is similar to this extruded conformation. ${ }^{46,59}$

The requirement of such tightly coupled structural changes for productive binding is particular to the base-displaced intercalated multi-ring cis- $\mathrm{B}[\mathrm{a}] \mathrm{P}-\mathrm{dG}$ lesion. In comparison, for the CPD-containing duplex, the small lesion becomes displaced as BHD2 and BHD3 bind to the lesion site; then the two mismatched partner $\mathrm{T}$ bases flip in concert to denature the lesion site with correlated extrusion of the CPD to the major groove (Figure 4) with a free energy barrier of $4.2 \mathrm{kcal} / \mathrm{mol}^{41}$ The full insertion of the BHD3 $\beta$-hairpin is spontaneous. The similar free energy barriers for the two damaged DNA sequences are in good agreement with the fact that $\mathrm{CPD}$ with mismatched partners and cis- $\mathrm{B}[a] \mathrm{P}-\mathrm{dG}$ with normal partner $\mathrm{C}$ are both well-repaired. ${ }^{8,42,43}$

Strong Initial Binding and a Sufficiently Low Free Energy Barrier for the Formation of the Denatured Open Complex Are Proposed to Be Required for Productive Lesion Recognition by Rad4/XPC. Stable productive binding of XPC to damaged DNA duplexes is required for the recruitment of subsequent factors in GG-NER that lead to successful repair. However, the molecular mechanism and associated energetics of XPC binding to different lesion-containing DNA duplexes remains a research frontier. Our studies of the Rad4 productive binding processes to two structurally different damaged DNAs reveal molecularly and energetically how two crucial factors determine the outcome of this essential lesion recognition step in GG-NER: (1) the nature of the Rad4/XPC initial binding to the damaged duplex and (2) the free energy barrier at the transition state, where the denatured open state with flipped partner bases has been achieved. Productive lesion recognition by the XPC would require strong initial binding and a sufficiently low energy barrier in the pathway to allow for the formation of the productive open complex. Strong initial binding would facilitate XPC stalling at the lesion site. Progress down the productive binding pathway can then ensue if the free energy barrier in the path is sufficiently low. These molecular and energetic understandings are in line with the "kinetic gating" mechanism proposed by Chen et al. ${ }^{40}$ Failures at either stage of XPC binding would interrupt the XPC lesion recognition step in GG-NER and therefore impact overall NER outcome. Repair resistant lesions have been observed to bind XPC, and we have hypothesized that such binding modes are nonproductive ones. $^{60}$

The relevance of our delineated binding pathway for Rad4 to human XPC is of considerable interest. Sequence alignment of Rad4 with XPC from multiple species including humans is discussed extensively in Min and Pavletich, notably in their Supplementary Figure 2. ${ }^{7}$ As detailed there, the BHD2-BHD3 residues that contact the damaged DNA are conserved in Rad4 and human XPC, indicating that critical contacts are maintained. However, there is a difference in the BHD2 hairpin length, namely, a 15 amino acid insertion in the XPC compared to that in Rad4. This suggests that the human XPC may bind more tightly to the damaged DNA than Rad4 via more extensive interactions involving the $\mathrm{BHD} 2$ hairpin tip. Binding studies with the adduct positioned at the 25th nucleotide from the 5 -end in 50-mer DNA duplexes have supported this suggestion. For the cis-B $[a] \mathrm{P}-\mathrm{dG}$ adduct, with human XPC and with Rad4 the binding studies have shown that the dissociation constant in the case of Rad4-Rad23 is $K_{d}=$ $8.2 \pm 0.35 \mathrm{nM}$; however, with XPC-RAD23B, $K_{d}=0.67 \pm 0.2$ $\mathrm{nM}$, and the $K_{d}(\operatorname{Rad} 4) / K_{d}(\mathrm{XPC})$ is $\sim 8 \pm 4 .^{60,61}$ Therefore, $\mathrm{XPC}$ has a higher binding affinity than $\operatorname{Rad} 4$ for the cis-B $[a] \mathrm{P}$ $\mathrm{dG}$ adduct; furthermore, the higher XPC binding affinity is also observed for other lesions derived from polycyclic aromatic hydrocarbons, as well as for unmodified DNA. ${ }^{61}$ A homology model (Mu et al., unpublished results) of human XPC with a CPD-containing DNA duplex in productive binding mode, based on the Rad4 crystal structure (PDB ID: 2QSG), shows that the BHD2 hairpin has more extensive contacts with the minor groove around the lesion site. However, BHD3 is similarly inserted as in productively bound Rad4; key contacts involving the inserted hairpin (e.g., Phe 599 in Rad4/Phe 799 in human XPC) and in the binding pockets for the flipped partners (e.g., Phe 597, Pro 607, Phe 556, Asn 554, Asn 558 in Rad4/Phe 797, Pro 806, Phe 756, Asn 754, and Asn 758 in human XPC) are conserved.

\section{CONCLUSION}

Lesion structural properties in DNA can impact how they are recognized by XPC; both initial recognition by $\mathrm{BHD} 2$ on the minor groove side of the duplex and/or lesion site denaturation by BHD3's interaction with the major groove are affected. These factors determine how well BHD2 binds on first encounter and the free energy barrier for denaturing the duplex to form the open complex. For the currently examined cis$\mathrm{B}[a] \mathrm{P}-\mathrm{dG}$, with its unique structure containing an extruded partner base $\mathrm{C}$ and an intercalated $\mathrm{B}[a] \mathrm{P}$ ring system, ${ }^{46}$ our results have shown how initial binding of the damaged DNA by the Rad4 is fostered by the displaced partner C. We also showed how the intercalated $\mathrm{B}[a] \mathrm{P}$ rings promote a tightly coupled correlated mechanism involving (1) BHD3 $\beta$-hairpin insertion from the major groove, (2) flipping of the second partner strand base into a three Phe "flipping path" for capture in its binding pocket, and (3) the extrusion of the $\mathrm{B}[a] \mathrm{P}$ rings into the minor groove. This pathway differs from that of the small CPD lesion ${ }^{41}$ whose structure in duplex DNA is very different. The possibility of various binding pathways for lesions with different impacts on DNA structure and stability may contribute to the versatility of productive lesion recognition by $\mathrm{XPC}$ that is required for successful NER.

\section{ASSOCIATED CONTENT}

\section{Supporting Information}

The Supporting Information is available free of charge on the ACS Publications website at DOI: 10.1021/acs.chemrestox.7b00074.

Movie of Rad4 productive binding to the cis- $\mathrm{B}[\mathrm{a}] \mathrm{P}-\mathrm{dG}$ containing duplex (.AVI.ZIP) 
Crystal structure of the productive open complex for Rad4 with a CPD-containing DNA duplex (PDB ID: 2QSG), reaction coordinates used for the preferred tightly coupled binding pathway, explored stepwise binding pathways, clustering of the structural ensemble of unrestrained $\mathrm{MD}$ simulation starting from the initial model, the initial binding of $\operatorname{Rad} 4$ to the cis-B $[a] \mathrm{P}-\mathrm{dG}$ containing DNA, best representative frames along the preferred binding pathway, and details of the best representative structures, DNA distortions around lesion site, and hydrogen bonds between BHD2-BHD3 and DNA (PDF)

\section{AUTHOR INFORMATION}

\section{Corresponding Author}

*Biology Department, New York University, 100 Washington Square East, 1009 Silver Center, New York, NY 10003. Tel: +1 212998 8231. Fax: +1 212995 4015. E-mail: broyde@nyu.edu. ORCID $\odot$

Suse Broyde: 0000-0002-3802-7511

\section{Funding}

This research was supported by National Institutes of Health (R01-ES025987, R01-CA28038, and R01-CA75449 to S.B., R01-GM079223 to Y.Z., and R01-ES024050 to N.E.G.); National Science Foundation (MCB-1412692 to J.-H.M.); and a start-up fund from the University of Illinois at Chicago (to J.-H.M.).

\section{Notes}

The authors declare no competing financial interest.

\section{ACKNOWLEDGMENTS}

This work used the Extreme Science and Engineering Discovery Environment (XSEDE), which is supported by National Science Foundation (NSF) Grant MCB060037, and the high performance computing resources of New York University (NYU-ITS).

\section{ABBREVIATIONS}

NER, nucleotide excision repair; cis-B[a]P-dG, 10R-(+)-cis-antibenzo $[a]$ pyrene- $N^{2}-\mathrm{dG}$; CPD, cis-syn cyclobutane pyrimidine dimer; UV, ultraviolet; GG-NER, global genomic NER; TCNER, transcription-coupled NER; Rad4, Saccharomyces cerevisiae Rad4-Rad23; TGD, transglutaminase domain; BHD1, betahairpin domain 1; BHD2, beta-hairpin domain 2; BHD3, betahairpin domain 3 ; T-jump, temperature-jump perturbation spectroscopy; FRET, fluorescence resonance energy transfer; $\mathrm{MD}$, molecular dynamics; $\mathrm{B}[a] \mathrm{P}$, benzo $[a]$ pyrene; vFEP, variational Free Energy Profile; $\mathrm{DB}[a, l] \mathrm{P}$, dibenzo $[a, l]$ pyrene

\section{REFERENCES}

(1) Spivak, G. (2015) Nucleotide excision repair in humans. DNA Repair 36, 13-18.

(2) Scharer, O. D. (2013) Nucleotide excision repair in eukaryotes. Cold Spring Harbor Perspect. Biol. 5, a012609.

(3) Wood, R. D. (1999) DNA damage recognition during nucleotide excision repair in mammalian cells. Biochimie 81, 39-44.

(4) Gillet, L. C., and Schärer, O. D. (2006) Molecular mechanisms of mammalian global genome nucleotide excision repair. Chem. Rev. 106, $253-276$.

(5) Gunz, D., Hess, M. T., and Naegeli, H. (1996) Recognition of DNA adducts by human nucleotide excision repair. Evidence for a thermodynamic probing mechanism. J. Biol. Chem. 271, 25089-25098.
(6) Geacintov, N. E., Broyde, S., Buterin, T., Naegeli, H., Wu, M., Yan, S., and Patel, D. J. (2002) Thermodynamic and structural factors in the removal of bulky DNA adducts by the nucleotide excision repair machinery. Biopolymers 65, 202-210.

(7) Min, J. H., and Pavletich, N. P. (2007) Recognition of DNA damage by the Rad4 nucleotide excision repair protein. Nature 449, $570-575$.

(8) Reeves, D. A., Mu, H., Kropachev, K., Cai, Y., Ding, S., Kolbanovskiy, A., Kolbanovskiy, M., Chen, Y., Krzeminski, J., Amin, S., Patel, D. J., Broyde, S., and Geacintov, N. E. (2011) Resistance of bulky DNA lesions to nucleotide excision repair can result from extensive aromatic lesion-base stacking interactions. Nucleic Acids Res. 39, 8752-8764.

(9) Cai, Y., Geacintov, N. E., and Broyde, S. (2012) Nucleotide excision repair efficiencies of bulky carcinogen-DNA adducts are governed by a balance between stabilizing and destabilizing interactions. Biochemistry 51, 1486-1499.

(10) Cai, Y., Zheng, H., Ding, S., Kropachev, K., Schwaid, A. G., Tang, Y., Mu, H., Wang, S., Geacintov, N. E., Zhang, Y., and Broyde, S. (2013) Free energy profiles of base flipping in intercalative polycyclic aromatic hydrocarbon-damaged DNA duplexes: energetic and structural relationships to nucleotide excision repair susceptibility. Chem. Res. Toxicol. 26, 1115-1125.

(11) Puumalainen, M. R., Ruthemann, P., Min, J. H., and Naegeli, H. (2016) Xeroderma pigmentosum group $\mathrm{C}$ sensor: unprecedented recognition strategy and tight spatiotemporal regulation. Cell. Mol. Life Sci. 73, 547-566.

(12) Sugasawa, K. (2016) Molecular mechanisms of DNA damage recognition for mammalian nucleotide excision repair. DNA Repair 44, $110-117$.

(13) Hanawalt, P. C., and Spivak, G. (2008) Transcription-coupled DNA repair: two decades of progress and surprises. Nat. Rev. Mol. Cell Biol. 9, 958-970.

(14) Vermeulen, W., and Fousteri, M. (2013) Mammalian transcription-coupled excision repair. Cold Spring Harbor Perspect. Biol. 5, a012625.

(15) Spivak, G. (2016) Transcription-coupled repair: an update. Arch. Toxicol. 90 (11), 2583-2594.

(16) Nishi, R., Okuda, Y., Watanabe, E., Mori, T., Iwai, S., Masutani, C., Sugasawa, K., and Hanaoka, F. (2005) Centrin 2 stimulates nucleotide excision repair by interacting with xeroderma pigmentosum group C protein. Mol. Cell. Biol. 25, 5664-5674.

(17) Fujiwara, Y., Masutani, C., Mizukoshi, T., Kondo, J., Hanaoka, F., and Iwai, S. (1999) Characterization of DNA recognition by the human UV-damaged DNA-binding protein. J. Biol. Chem. 274, 2002720033.

(18) Li, T., Chen, X., Garbutt, K. C., Zhou, P., and Zheng, N. (2006) Structure of DDB1 in complex with a paramyxovirus V protein: viral hijack of a propeller cluster in ubiquitin ligase. Cell 124, 105-117.

(19) Scrima, A., Konickova, R., Czyzewski, B. K., Kawasaki, Y., Jeffrey, P. D., Groisman, R., Nakatani, Y., Iwai, S., Pavletich, N. P., and Thoma, N. H. (2008) Structural basis of UV DNA-damage recognition by the DDB1-DDB2 complex. Cell 135, 1213-1223.

(20) Ghodke, H., Wang, H., Hsieh, C. L., Woldemeskel, S., Watkins, S. C., Rapic-Otrin, V., and Van Houten, B. (2014) Single-molecule analysis reveals human UV-damaged DNA-binding protein (UVDDB) dimerizes on DNA via multiple kinetic intermediates. Proc. Natl. Acad. Sci. U. S. A. 111, E1862-1871.

(21) Sugasawa, K. (2011) Multiple DNA damage recognition factors involved in mammalian nucleotide excision repair. Biochemistry (Moscow) 76, 16-23.

(22) Yeh, J. I., Levine, A. S., Du, S., Chinte, U., Ghodke, H., Wang, H., Shi, H., Hsieh, C. L., Conway, J. F., Van Houten, B., and RapicOtrin, V. (2012) Damaged DNA induced UV-damaged DNA-binding protein (UV-DDB) dimerization and its roles in chromatinized DNA repair. Proc. Natl. Acad. Sci. U. S. A. 109, E2737-2746.

(23) Coin, F., Oksenych, V., and Egly, J. M. (2007) Distinct roles for the $\mathrm{XPB} / \mathrm{p} 52$ and $\mathrm{XPD} / \mathrm{p} 44$ subcomplexes of TFIIH in damaged 
DNA opening during nucleotide excision repair. Mol. Cell 26, 245256.

(24) Mathieu, N., Kaczmarek, N., Ruthemann, P., Luch, A., and Naegeli, H. (2013) DNA quality control by a lesion sensor pocket of the xeroderma pigmentosum group D helicase subunit of TFIIH. Curr. Biol. 23, 204-212.

(25) Li, C. L., Golebiowski, F. M., Onishi, Y., Samara, N. L., Sugasawa, K., and Yang, W. (2015) Tripartite DNA Lesion Recognition and Verification by XPC, TFIIH, and XPA in Nucleotide Excision Repair. Mol. Cell 59, 1025-1034.

(26) Spies, M. (2014) Two steps forward, one step back: determining XPD helicase mechanism by single-molecule fluorescence and highresolution optical tweezers. DNA Repair 20, 58-70.

(27) Wirth, N., Gross, J., Roth, H. M., Buechner, C. N., Kisker, C., and Tessmer, I. (2016) Conservation and Divergence in Nucleotide Excision Repair Lesion Recognition. J. Biol. Chem. 291, 18932-18946.

(28) Chen, R., Subramanyam, S., Elcock, A. H., Spies, M., and Wold, M. S. (2016) Dynamic binding of replication protein a is required for DNA repair. Nucleic Acids Res. 44, 5758-5772.

(29) Kong, M., Liu, L., Chen, X., Driscoll, K. I., Mao, P., Bohm, S., Kad, N. M., Watkins, S. C., Bernstein, K. A., Wyrick, J. J., Min, J. H., and Van Houten, B. (2016) Single-Molecule Imaging Reveals that Rad4 Employs a Dynamic DNA Damage Recognition Process. Mol. Cell 64, 376-387.

(30) Volker, M., Mone, M. J., Karmakar, P., van Hoffen, A., Schul, W., Vermeulen, W., Hoeijmakers, J. H., van Driel, R., van Zeeland, A. A., and Mullenders, L. H. (2001) Sequential assembly of the nucleotide excision repair factors in vivo. Mol. Cell 8, 213-224.

(31) Riedl, T., Hanaoka, F., and Egly, J. M. (2003) The comings and goings of nucleotide excision repair factors on damaged DNA. EMBO J. 22, 5293-5303.

(32) Luijsterburg, M. S., von Bornstaedt, G., Gourdin, A. M., Politi, A. Z., Mone, M. J., Warmerdam, D. O., Goedhart, J., Vermeulen, W., van Driel, R., and Hofer, T. (2010) Stochastic and reversible assembly of a multiprotein DNA repair complex ensures accurate target site recognition and efficient repair. J. Cell Biol. 189, 445-463.

(33) Hey, T., Lipps, G., Sugasawa, K., Iwai, S., Hanaoka, F., and Krauss, G. (2002) The XPC-HR23B complex displays high affinity and specificity for damaged DNA in a true-equilibrium fluorescence assay. Biochemistry 41, 6583-6587.

(34) Naegeli, H., and Sugasawa, K. (2011) The xeroderma pigmentosum pathway: decision tree analysis of DNA quality. DNA Repair 10, 673-683.

(35) Sugasawa, K., Akagi, J., Nishi, R., Iwai, S., and Hanaoka, F. (2009) Two-step recognition of DNA damage for mammalian nucleotide excision repair: Directional binding of the XPC complex and DNA strand scanning. Mol. Cell 36, 642-653.

(36) Sugasawa, K., Ng, J. M., Masutani, C., Iwai, S., van der Spek, P. J., Eker, A. P., Hanaoka, F., Bootsma, D., and Hoeijmakers, J. H. (1998) Xeroderma pigmentosum group $C$ protein complex is the initiator of global genome nucleotide excision repair. Mol. Cell 2, 223232.

(37) Sugasawa, K., Shimizu, Y., Iwai, S., and Hanaoka, F. (2002) A molecular mechanism for DNA damage recognition by the xeroderma pigmentosum group C protein complex. DNA Repair 1, 95-107.

(38) Friedberg, E. C., Walker, G. C., Siede, W., Wood, R. D., Schultz, R. A., and Ellenberger, T. (2005) DNA Repair and Mutagenesis, 2nd ed., ASM Press, Washington, DC.

(39) Velmurugu, Y., Chen, X., Slogoff Sevilla, P., Min, J. H., and Ansari, A. (2016) Twist-open mechanism of DNA damage recognition by the Rad4/XPC nucleotide excision repair complex. Proc. Natl. Acad. Sci. U. S. A. 113, E2296-2305.

(40) Chen, X., Velmurugu, Y., Zheng, G., Park, B., Shim, Y., Kim, Y., Liu, L., Van Houten, B., He, C., Ansari, A., and Min, J. H. (2015) Kinetic gating mechanism of DNA damage recognition by Rad4/XPC. Nat. Commun. 6, 5849.

(41) Mu, H., Geacintov, N. E., Zhang, Y., and Broyde, S. (2015) Recognition of Damaged DNA for Nucleotide Excision Repair: A
Correlated Motion Mechanism with a Mismatched cis-syn Thymine Dimer Lesion. Biochemistry 54, 5263-5267.

(42) Mu, D., Tursun, M., Duckett, D. R., Drummond, J. T., Modrich, P., and Sancar, A. (1997) Recognition and repair of compound DNA lesions (base damage and mismatch) by human mismatch repair and excision repair systems. Mol. Cell. Biol. 17, 760-769.

(43) Sugasawa, K., Okamoto, T., Shimizu, Y., Masutani, C., Iwai, S., and Hanaoka, F. (2001) A multistep damage recognition mechanism for global genomic nucleotide excision repair. Genes Dev. 15, 507-521.

(44) Hess, M. T., Gunz, D., Luneva, N., Geacintov, N. E., and Naegeli, H. (1997) Base pair conformation-dependent excision of benzo[a]pyrene diol epoxide-guanine adducts by human nucleotide excision repair enzymes. Mol. Cell. Biol. 17, 7069-7076.

(45) Mocquet, V., Kropachev, K., Kolbanovskiy, M., Kolbanovskiy, A., Tapias, A., Cai, Y., Broyde, S., Geacintov, N. E., and Egly, J. M. (2007) The human DNA repair factor XPC-HR23B distinguishes stereoisomeric benzo[a]pyrenyl-DNA lesions. EMBO J. 26, 29232932.

(46) Cosman, M., de los Santos, C., Fiala, R., Hingerty, B. E., Ibanez, V., Luna, E., Harvey, R., Geacintov, N. E., Broyde, S., and Patel, D. J. (1993) Solution conformation of the (+)-cis-anti-[BP]dG adduct in a DNA duplex: intercalation of the covalently attached benzo $[a]$ pyrenyl ring into the helix and displacement of the modified deoxyguanosine. Biochemistry 32, 4145-4155.

(47) Buterin, T., Meyer, C., Giese, B., and Naegeli, H. (2005) DNA quality control by conformational readout on the undamaged strand of the double helix. Chem. Biol. 12, 913-922.

(48) Phillips, D. H. (1983) Fifty years of benzo(a)pyrene. Nature 303, 468-472.

(49) Geacintov, N. E., Cosman, M., Hingerty, B. E., Amin, S., Broyde, S., and Patel, D. J. (1997) NMR solution structures of stereoisometric covalent polycyclic aromatic carcinogen-DNA adduct: principles, patterns, and diversity. Chem. Res. Toxicol. 10, 111-146.

(50) Abdel-Shafy, H. I., and Mansour, M. S. M. (2016) A review on polycyclic aromatic hydrocarbons: Source, environmental impact, effect on human health and remediation. Egypt. J. Pet. 25, 107-123.

(51) Roux, B. (1995) The calculation of the potential of mean force using computer simulations. Comput. Phys. Commun. 91, 275-282.

(52) Case, D. A., Babin, V., Berryman, J. T., Betz, R. M., Cai, Q., Cerutti, D. S., Cheatham, T. E., III, Darden, T. A., Duke, R. E., Gohlke, H., Goetz, A. W., Gusarov, S., Homeyer, N., Janowski, P., Kaus, J., Kolossváry, I., Kovalenko, A., Lee, T. S., LeGrand, S., Luchko, T., Luo, R., Madej, B., Merz, K. M., Paesani, F., Roe, D. R., Roitberg, A., Sagui, C., Salomon-Ferrer, R., Seabra, G., Simmerling, C. L., Smith, W., Swails, J., Walker, R. C., Wang, J., Wolf, R. M., Wu, X., and Kollman, P. A. (2014) AMBER14, University of California, San Francisco, CA.

(53) Maier, J. A., Martinez, C., Kasavajhala, K., Wickstrom, L., Hauser, K. E., and Simmerling, C. (2015) ff14SB: Improving the Accuracy of Protein Side Chain and Backbone Parameters from ff99SB. J. Chem. Theory Comput. 11, 3696-3713.

(54) Lee, T. S., Radak, B. K., Huang, M., Wong, K. Y., and York, D. M. (2014) Roadmaps through free energy landscapes calculated using the multi-dimensional vFEP approach. J. Chem. Theory Comput. 10, 24-34.

(55) Lavery, R., Moakher, M., Maddocks, J. H., Petkeviciute, D., and Zakrzewska, K. (2009) Conformational analysis of nucleic acids revisited: Curves+. Nucleic Acids Res. 37, 5917-5929.

(56) Camenisch, U., Trautlein, D., Clement, F. C., Fei, J., Leitenstorfer, A., Ferrando-May, E., and Naegeli, H. (2009) Twostage dynamic DNA quality check by xeroderma pigmentosum group C protein. EMBO J. 28, 2387-2399.

(57) Park, H., Zhang, K., Ren, Y., Nadji, S., Sinha, N., Taylor, J. S., and Kang, C. (2002) Crystal structure of a DNA decamer containing a cis-syn thymine dimer. Proc. Natl. Acad. Sci. U. S. A. 99, 15965-15970.

(58) Lee, J. H., Park, C. J., Shin, J. S., Ikegami, T., Akutsu, H., and Choi, B. S. (2004) NMR structure of the DNA decamer duplex containing double $T^{*} \mathrm{G}$ mismatches of cis-syn cyclobutane pyrimidine dimer: implications for DNA damage recognition by the XPChHR23B complex. Nucleic Acids Res. 32, 2474-2481. 
(59) Xie, X. M., Geacintov, N. E., and Broyde, S. (1999) Origins of conformational differences between cis and trans DNA adducts derived from enantiomeric anti-benzo[a]pyrene diol epoxides. Chem. Res. Toxicol. 12, 597-609.

(60) Lee, Y. C., Cai, Y., Mu, H., Broyde, S., Amin, S., Chen, X., Min, J. H., and Geacintov, N. E. (2014) The relationships between XPC binding to conformationally diverse DNA adducts and their excision by the human NER system: is there a correlation? DNA Repair 19, 55-63.

(61) Lee, Y. C. (2015) Translesion Synthesis of Bulky DNA Lesions and Relationships between Adduct Recognition and Nucleotide Excision Repair Efficiencies, Ph.D. Dissertation, New York University, New York, NY.

(62) Lu, X. J., and Olson, W. K. (2003) 3DNA: a software package for the analysis, rebuilding and visualization of three-dimensional nucleic acid structures. Nucleic Acids Res. 31, 5108-5121. 